\title{
FACTORS INFLUENCING PARENTAL CONTROL FOR THE SAFE AND PEDAGOGICAL INTERNET USE AMONG PRIMARY SCHOOL STUDENTS
}

\author{
Elena Vitalaki, Panagiotes S. Anastasiades \\ University of Crete, Greece \\ E-mail: vitalaki@edc.uoc.gr
}

George Tsouvelas

National Kapodistrian University of Athens, Greece

\begin{abstract}
Due to the increasing children's use of the Internet at home and at school as well as that inappropriate Internet content may jeopardize their health or safety, the aim of the present study is twofold: a) to examine parents 'perceptions of the degree to which children may be exposed to negative Internet content, and b) to find out the differences in parents' attitudes to the use of the Internet by students of $4^{\text {th }}, 5^{\text {th }}$ and $6^{\text {th }}$ grade, as an acknowledgment of being an important part of their children's day-to-day educational and interpersonal life. 1503 questionnaires from urban and rural provinces of Crete demonstrate that parents' technological efficacy is strongly related to their better evaluation of the Internet hazards and their effectiveness in promoting Internet safety awareness when navigating with their children at home.
\end{abstract}

Key words: Internet safety awareness, factors, parental control, primary school.

\section{Introduction}

As many recent studies describe the digital divide in terms of increasing access and use among children (Subrahmanyam and Greenfield, 1999), discomfort with technology and a desire whether or not to take responsibility for their child's instruction in using it, reflect most parents' inexperience with ICT (Anastasiades, Vitalaki and Gertzakis, 2008; Linebarger and Chernin, 2003). On the other hand, parents who desire to use technology effectively can greatly enhance the technological gap between them and their children by using the Internet as a shared household activity (Mesch, 2003). Though, current findings reveal that parents who can use the Internet as a positive and developmental tool for their family are usually educated and familiar with the technology (Anastasiades, Vitalaki and Gertzakis, 2008; Valcke, Schellens, Van Keerand, Gerarts, 2007; Cho and Cheon, 2005; Linebarger and Chernin, 2003; Mesch, 2003; Corbett and Willms, 2002).

Regarding the introduction of ICT in class, the availability of computers at schools enables most students to use technology even though some may not have a computer at home. Also, as to provide students with increased technological skills and preparedness to succeed and excel, the penetration of technology in the school classroom is expected to improve the pre-mentioned educational outcomes (Corbett and Willms, 2002; Pelgrum and Anderson 1999). Despite the number of computers in schools and the fact that numerous children around the world are accessing the Internet from the classroom over the past few years, ICT remains a contentious issue for many teachers at the point of implementation. Attitudes to whether, how and why it 
PROBLEMS

OF EDUCATION

IN THE $21^{\text {st }}$ CENTURY

Volume 42, 2012

126

should be used for teaching and learning are very varied. Also, less attention has been devoted to helping school administrators and teachers understand their specific options, technological or otherwise, for protecting children when they access the Internet over a school-based or statewide educational network. According to Valcke, Schellens, Van Keerand and Gerarts (2007), there is a general awareness from educators to promote school-based interventions in order to support safe Internet use by students.

Recognizing the ever-serious aspects of children using the Internet at home and at school and parents' possible underestimation of, or ignorance about, their children's Internet usage and its developmental effects, this study explores the impact of the integration of computers in the Greek family and explores the level of parental capacity to provide safe practices and wise pedagogical guidance to primary school students. Particularly, the notion of the parents' level of familiarity with the Internet use and their ability to promote Internet safety behaviors at home, was also explored.

\section{Problems of the Research}

Protecting children from harmful Internet content has been a growing concern for the past few years for parents, educators and scientists, who are increasingly sceptical about the influence of ICT on children and express disappointment over their children using the computer for various activities (e.g. playing video games, communicating with other people or searching for information etc.) (Linebarger and Chernin, 2003; Subrahmanyam et al, 2001). Though, having a computer and Internet access at home is associated with more comfort with technology and a sense that children with no technology at home might not be provided with the "right" educational opportunities in the "information age" (Plowman, McPake and Stephen, 2010; Anastasiades et al, 2008; Fairlie, 2005; Facer Keri, Furlong John, Furlong Ruth and Sutherland Rosamund, 2003; Cordes and Miller, 2000). Also, most parents have a tendency to appreciate more time wasted on the computer by their children than to time wasted on TV (Subrahmanyam, Greenfield, Kraut and Gross, 2001). Though, according to Anastasiades and Vitalaki, (2004) some parents feel helpless at the beginning of this new digital era while others wholeheartedly consider it as an important part of their children's educational and developmental process. When examining computer and Internet attitudes as a whole, it appears that recent families are ambivalent about the new technologies (Plowman, McPake and Stephen, 2010).

Research findings suggest that although many parents consider the introduction of home computer as an important educational tool for their children, they worry that they are not enough equipped with the sufficient skills to navigate the Web and feel quite uncomfortable using the computer along with their children (Linebarger and Chernin, 2003; Subrahmanyam, Greenfield, Kraut and Gross, 2001). To the writers' view, this attitude may derive from the parents' tension to support that schools should take the lead in educating their children to surf the web safely and productively or that a computer is mostly used for educational purposes rather than for entertainment and that their children are not at a disadvantage for not having Internet access at home or at school (Subrahmanyam, Greenfield, Kraut and Gross, 2001). However, a number of studies indicate that when the Internet use at home is considered a shared household activity, this can minimize the possible online risks a child may encounter on the Net as well as the negative developmental affects (Wang, Bianchi and Raley, 2005; Amato and Fowler, 2002) or delinquent behaviour problems in early adolescence (Pettit, Laird, Dodge, Bates and Criss, 2001). In conclusion, the above findings assume that when parents use the Internet along with their children, this is linked to a higher level of parental monitoring.

According to Wang et al, (2005) there are various factors concerning Internet rule setting within a household, such as parents' gender, socio-cultural settings, technical knowledge and marital state. For example, parents from urban socio-cultural settings more than rural regions, 
Elena VITALAKI, Panagiotes S. ANASTASIADES, George TSOUVELAS. Factors Influencing Parental Control for the Safe and Pedagogical Internet Use among Primary School Students

with better computer and Internet knowledge (Anastasiades et al, 2008; Wang et al, 2005; Pettersson and Carlsson, 2004; Zhu and He, 2002; Corbett and Willms, 2002), and married parents more than single ones (Lugaila, 2003), may feel better able to monitor their children's Internet usage and are more involved in their online activities for education and amusement. Also, recent findings report that mothers are more likely to check their children's new learning and interpersonal experiences through Internet use than fathers due to the fact that mothers tend to be more communicative and spend more time with children at home than fathers do (Anastasiades et al, 2008; Sayer, Bianchi and Robinson, 2004). However, mothers are less instructive and monitoring than fathers when children use the home computer given that fathers demonstrate better technological efficiency than mothers do (Anastasiades et al, 2008; Wang et al, 2005; Pettersson and Carlsson, 2004). Finally, little is known about the variables that characterize "effective parenting" especially when children demonstrate greater technological efficiency than parents (Plowman, McPake and Stephen, 2010; also see Tein, Roosa and Michaels, 1994, p. 342) and the discrepancy that might exist between parents and children when the first are faced with the opportunity to act as mentors for the decisions their children must take when surfing the Web.

Mesch (2003) found that extensive use of the Internet by adolescents can lead to intergenerational conflicts (e.g. conflicts over privacy, computer time use, and gaps in expectations) especially when this is not used for learning purposes. Also, despite the fact that time spent together builds positive relations between parents and children, this does not preoccupy the possibility that the Internet usage as a shared household activity will increase the quality of closeness of adolescents to parents. And this because, the quality of closeness or the amount of conflicts within the family depend on how parents evaluate the type of the Internet usage by children (for example, whether surfing the Net is done for education or amusement purposes) and in what way this parental consideration may affect the adolescents' perceived closeness to their parents.

In sum, the positive role of parent-child interaction on media usage to the Internet may result to better decision making and agreement on which Internet activities may be considered as harmful or not and a higher control over children's behaviors (perceived control over their children's Internet usage) especially before adolescence (Wang, Bianchi and Raley, 2005; Cho and Cheon, 2005). Unfortunately, additional studies support that parents usually underestimate the possible dangers a child may encounter on the Net (Anastasiades et al, 2008; European Opinion Research Group EEIG-Special Eurobarometer, 2004; Attewell, Suazo-Garcia and Battle, 2003; Pew Internet and American Life Report, 2001; Yankelovich Partners, 1999). Overall, parental attitudes and perspectives of the introduction of ICT in children's everyday life raises major issues on how the role of family environment affects children's critical choice to navigate the Internet safely or not.

\section{Methodology of Research}

\section{General Description of Research}

Recognizing the importance of parents' involvement in children's safe and pedagogical use of the Internet in and out the family home, this study examines which factors contribute to children's less exposure to harmful Internet content regarding parents' attitudes and perceptions when children use the Internet for various activities. It is aimed to do this from three main perspectives: a) parents' attitudes towards children when they surf the Internet at home, b) to what extend can parents identify risky Internet usage by children, c) whether parents are capable of guiding young users to avoid the dangers that may be encountered on the Web.

Finally, the significance of this study lies to the fundamental need of parents to become 
PROBLEMS

OF EDUCATION

IN THE $21^{\text {st }}$ CENTURY Volume 42, 2012

128

the present research emphasizes the need for guiding or giving directions to parents in safety Internet issues that build on a more safe engagement of primary students within the family.

\section{Hypotheses of Research}

For the needs of this study the researchers designed questions concerning: a) parents' technological grasp of Internet access, b) their attitudes towards their children's opportunity to use ICT for educational and interpersonal activities in and out the family home, c) how parents evaluate their children's possible exposure to negative Internet, d) which parents consider themselves capable enough to promote Internet Safety matters with children (what gender and in which locations-developed or developing societies), e) what Internet safety actions usually take place within the family, and f) where parents currently get advice from on Internet Safety and how they respond to that advice.

More specifically, the assumptions tested here are:

a) Parents' technological grasp leads to a better evaluation of the Internet dangers and their serious affects on children's psycho-physical development.

b) Higher technological profiles affect significantly parents' level of involvement in shared educational and recreational activities with children through the Web.

c) Parents' who tend to be more communicative concerning their children's new learning and interpersonal experiences through Internet use are more likely to promote Internet safety behaviours in and out the family home.

d) The parents' effectiveness to promote Internet safety issues at home is also connected to the type of guidance they have already received.

\section{Sample and Research}

The present research covered a representative sample of 1503 parents of primary school students in urban and rural provinces of Crete. The sampling procedure began with a sample of the students' parents from the 4 main prefectures in the island of Crete with almost 25 primary schools in each prefecture or more. Then, according to the students' population in each school, 36 schools were randomly selected. The selected schools recruited the students' parents of $4^{\text {th }}, 5^{\text {th }}$ and $6^{\text {th }}$ grade to participate in the present research. Regarding the parents' gender, 550 (36. 8\%) were fathers and 946 (63. 2\%) were mothers. Parent' age ranged from 35 years to 45 years old. The selected sample of parents represents all geographic areas of Crete, and also different sized school populations, from big cities to small towns and villages. This research was supported by a grant from the Greek International Foundation of Scholarships

\section{Procedure and Research Tools}

To recruit families for this study, the researchers first contacted the principal of the school. After getting permission from the principal and teachers at the school, permission (consent) was obtained from parents or guardians too. Then, the survey questionnaire was delivered to the parents at home by the students. One family was randomly selected if they had multiple children at the same school. Finally, only one questionnaire was sent to each family and allowed parents to decide whether it would be completed by the mother or the father of the student. All Likert-type questions are coded 1 and 2 for strong negative and negative answer, 3 for not knowing and 4 and 5 for less positive and more positive. 
Elena VITALAKI, Panagiotes S. ANASTASIADES, George TSOUVELAS. Factors Influencing Parental Control for the Safe and Pedagogical Internet Use among Primary School Students

\section{Data Analysis}

The electronic data of the questionnaires were blueprinted and a content analysis of the text was conducted. Data analysis was performed right after the questionnaires were filled in by the parents. All statistical analysis of the data was performed using SPSS statistical package (Howitt and Cramer, 2004). For questions collecting quantitative data, frequencies of the responses to each question were calculated and cross-tabulations of the results were made. Also, $t$ test analyses were conducted to evaluate the differences between mothers and fathers in promoting Internet issues according to their technological profile. A $2 \times 2$ between subjects analysis of covariance was performed on the indicator parents' evaluation of the Internet hazards a child may encounter on the Internet. Independent variables consisted of parents' ability to protect their children from any possible risks on the Net (sufficient, insufficient) and discuss with their children about the possible negative Internet effects to their psycho-social development (sufficient, insufficient), factorially combined. Covariate was parent's technological profile.

\section{Results of Research}

Concerning the parents' level of technological profile the present study showed that although $35.9 \%$ of the parents claimed that had some relevant knowledge of computers, only $10.4 \%$ surfed the Web regularly while $42.8 \%$ did not use the Internet at all (Table 1). Finally, focusing on the gender differences in the level of the Internet use the present data revealed differences between the two sexes of the sample as fathers seemed more skillful users of the Internet than mothers (Figure 1).

Table 1. Parents' ability to navigate the Internet.

\begin{tabular}{|c|c|c|}
\hline \multicolumn{3}{|c|}{ Internet Use } \\
\hline & Frequency & Valid Percent \\
\hline A lot & 153 & 10.4 \\
\hline Enough & 289 & 19.6 \\
\hline A little & 403 & 27.3 \\
\hline Not at all & 633 & 42.8 \\
\hline
\end{tabular}

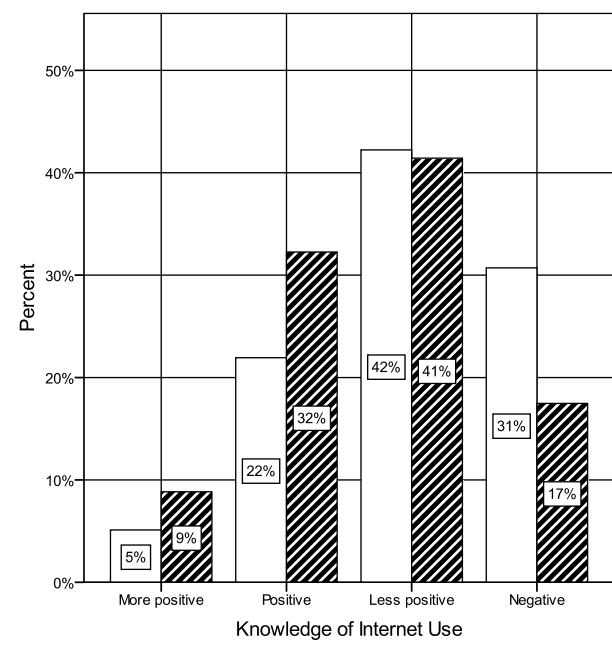

Figure 1: Gender differences in the level of the Internet use. 
PROBLEMS

OF EDUCATION

IN THE $21^{\text {st }}$ CENTURY

Volume 42,2012
According to the parents' attitudes about their children's possible engagement in new educational and interpersonal activities through the computer and the Internet outside the family home, more statistical differences were also detected between the two sexes of the sample. Specifically, fathers' evaluation of their children's educational needs and interpersonal experiences through the Web at home and at school $(M=2.01, S D=0.79)$ was better than mothers' $(M=1.92, S D=0.74), t(1087.544)=4.09, p<0.001$. Moreover, fathers were found more cautious about the extended and uncontrollable Internet use by children $(M=2.40, S D=0.87)$ than mothers $\operatorname{did}(M=2.16, S D=0.84), t(1453)=5.08, p<0.001$ (Table 2$)$.

Table 2. Fathers' and mothers' emerging Internet thoughts.

\begin{tabular}{|c|c|c|c|c|c|c|}
\hline & \multicolumn{6}{|c|}{ Sex } \\
\hline & \multicolumn{2}{|c|}{ Father } & \multicolumn{2}{|c|}{ Mother } & \multirow{2}{*}{$d f$} & \multirow[t]{2}{*}{$t$-test } \\
\hline & $M$ & $S D$ & M & SD & & \\
\hline $\begin{array}{l}\text { Fathers' and moth- } \\
\text { ers' emerging Internet } \\
\text { thoughts of the possible } \\
\text { negative factors by uncon- } \\
\text { trollable Internet use by } \\
\text { children }\end{array}$ & 2.01 & 0.79 & 1.92 & 0.79 & 1087.54 & $4.09^{*+* x}$ \\
\hline $\begin{array}{l}\text { Parents' technological } \\
\text { profile }\end{array}$ & 2.40 & 0.87 & 2.16 & 0.84 & 1453 & $5.08^{*+*+}$ \\
\hline
\end{tabular}

Moreover, parents with more technological knowledge appeared to have more negative attitude towards their children's opportunity to order and buy goods through the Web than online chatting with unknown persons or exposition to pornographic material as somebody would expect. The present results are analytically presented in Table 3.

Table 3. Parents' evaluation of children's possible exposure to specific types of negative Internet content.

\begin{tabular}{|l|c|c|}
\hline & $M$ & $S D$ \\
\hline Online uncontrollable purchases & 2.58 & 1.28 \\
\hline Luck of interaction with peers & 2.09 & 1.11 \\
\hline Adoption of negative attitudes and thoughts & 2.06 & 1.08 \\
\hline Physical interference & 1.99 & 1.04 \\
\hline Sexual abuse & 1.92 & 1.06 \\
\hline Adoption of violent behavior & 1.91 & 1.00 \\
\hline Online chatting with unknown persons & 1.76 & 1.08 \\
\hline Exposition to pornographic material & 1.61 & 0.95 \\
\hline
\end{tabular}

After adjustment of the covariate the predicted main effect of all independent factors was significant $F(1.1406)=8.71, p<0.001 \eta p^{2}=0.024$. The predicted main effect of discussion about the parents' technological profile was significant $F(1.1406)=4.22, p<0.05 \eta p^{2}=0.03$. The predicted main effect of discussion with their children about the possible negative Internet 
effects to their psycho-social development $F(1.1406)=32.56, p<0.001 \eta p^{2}=0.02$. The predicted main effect of parents' ability to protect their children from any possible risks on the Net, was no significant $F(1.1406)=1.23, p=0.27, \eta \mathrm{p} 2=.001$. The interaction between discussion with their children about the possible negative Internet effects to their psycho-social development and parents' ability to protect their children from any possible risks on the Net was significant, $F(1.1406)=5.78, p<0.05, \eta p^{2}<0.004$. So, parents who discuss the negative psychological effects of uncontrollable Internet use with their children tend to feel more capable to protect them from Internet hazards regardless of their technological profiles.

Finally, when parents were asked to emphasize which factors contribute to effective Net safety guidance within the family, $31 \%$ did not know how, $16 \%$ were self-learners, while the rest of the sample emphasized the importance of the school and various national policies as a way of enhancing their technological gap and ignorance in Internet safety matters.

\section{Discussion}

The current study detects how parents of primary school students from urban and rural provinces of Crete perceive the issue of the possible dangers that children may face when surfing the Net for educational or recreational activities. Particularly, the extent to which parents promote Internet safety behaviours according to their level of technological familiarity within the family, was also investigated.

An overall review of the present findings indicated that parents generally underestimate their children's exposure to negative Internet content (Valcke et al, 2007; Cho and Cheon, 2005; Gross, 2004), despite that most of the participants claimed that they knew the possible risks a child may encounter on the Net. This finding suggests that parents' insufficiency to practice technological interactivity with their children as an alternative form of human communication (see Anastasiades et al, 2008; Plowman and Stephen, 2005) may lead to a more frivolous use of the Internet by children than what most parents expect (Cho and Cheon, 2005).

Specifically, according to the parents' technological profiles almost half of the sample lucked the skills to navigate the Web. Fathers showed more sophisticated Internet skills than mothers (Anastasiades et al, 2008; Michie, and Nelson, 2006; Mwesige, 2004; Wong, 2002). Moreover, better skilled parents practiced more sophisticated interactivity with children through the Web than parents less technologically skilful (Plowman, McPake and Stephen, 2010). Finally, mothers of the whole sample were found less attracted to computers due to their luck of technological competence (Veckiri and Chronaki, 2008; Anastasiades et al, 2008; Michie, and Nelson, 2006; Mwesige, 2004; Colley and Comber, 2003; King, Bond and Blandford, 2002; Wong, 2002). As observed by other studies, this is usually expected by fathers to do given that fathers usually have more experience with computer technology (Wang et al, 2005; Pettersson and Carlsson, 2004).

Regarding parents' perception of the possible risks that a child may encounter on the Net, the present study found that parent's concerns about the effects of the Internet on children is affected by the level of technological capacity (Anastasiades et al, 2008; Linebarger and Chernin, 2003; Subrahmanyam, Greenfield, Kraut and Gross, 2001). Moreover, parents with insufficient knowledge regarding software did not seem to evaluate enough some serious types of negative Internet risks that may jeopardize children's developmental process (Anastasiades et al, 2008; Vandewater, Park, Huang and Wartellios, 2005; Lugaila, 2003). For example, regarding children's prospect to buy goods through the Web seemed more provocative to parents who had had much experience with the Internet than to parents with less technological skills. Moreover, similar to other studies, parents with firsthand Internet knowledge tend to reinforce their children's physical contact with peers and usually are less open to the possibility that one day their children might substitute the physical contact of their peers for alternative digital 
PROBLEMS

OF EDUCATION

IN THE $21^{\text {st }}$ CENTURY

Volume 42,2012

132

ones on the screen (Anastasiades et al, 2008). Given parents' inspectional behavior in relation to their children's unsuitable contact with unknown people, other types of negative effects on children's psycho-social and physical development such as, adoption of negative/violent behavior, physical interference (lack of sleep, obesity or eye damage) or luck of interaction with peers seemed to cause less interference to parents with technological sufficiency than to parents less technologically skilled, meaning that parents who use the Internet seem more competent to enforce rules and are more likely to monitor their children's digital activities than those who do not (Vandewater et al, 2005; Sothern, 2004; Lugaila, 2003; Yeora, 2003; Amato and Fowler, 2002; Pettit, Laird, Dodge, Bates and Criss, 2001; Greenberg, Rampoldi-Hnilo and Mastro, 2001).

As to the importance of supervision by parents when children navigate the Internet for amusement or education, there is clear evidence that parents have an impact on the safe Internet behaviour of their children (Anastasiades et al, 2008; Valcke et al, 2007; Cho and Cheon, 2005). Though, in contrast with Cho and Cheon's (2005) finding for the non effect of parents' Internet skill on control over children's Internet usage, the present research confirmed that parents' response with better technological sufficiency was highly positive correlated with the prevention of problematic use of the Internet by primary school students (Wang et al, 2005; Linebarger and Chernin, 2003). Finally, a further data analyses showed that regardless of the parents' technological backgrounds, these ones who tend to discuss Internet safety issues with children and even share online activities together are more likely to have higher control over their children's Internet usage. The result is consistent with previous studies on the role of shared family activities on parent-child mutual understanding (Shaw and Dawson, 2001; Stafford and Canary, 1991) and children's digital usage and learning (Anastasiades et al, 2008; Valcke et al, 2007; Cho and Cheon, 2005).

In conclusion, justified by the above findings and previous researches, the present study further confirms the importance of shared family activities in the context of children's negative Internet exposure. Parents who tend to incorporate safe Internet usage in the pedagogy of their children by discussing the negative psychological effects of uncontrollable Internet use are more effective to protect their children when they navigate the Web regardless of their technological profiles (Anastasiades et al, 2008; Cho and Cheon, 2005; Wang et al, 2005; Amato and Fowler, 2002; Pettit, Laird, Dodge, Bates and Criss, 2001).

Generally, a serious amount of parents express low self esteem to control unsafe Internet practices within the family while the rest of the sample relies on their personal judgements. Due to this, emphasis was given to the vital role of school-family communication and other national policies as a way of guiding parents to monitor or engage with their children over the pedagogical and moral use of the Internet.

\section{Conclusions}

In sum, this study has provided an exploratory framework for understanding the role of parents' perceptions and attitudes towards the integration of the computers and mostly the Internet into children's everyday educational and recreational activities at home or at school. Findings of this study showed that parental level of awareness and concerns of the possible risks that a child may encounter on the Web was significantly associated to families' technological profiles and gender. It was not surprising that parents with higher grasp of the web based technologies showed more awareness of the Internet dangers and of the serious effects on their children's psycho-social and physical development. Furthermore, parents who tend to take a more active role in their children's Internet activities, surf together and discuss Internet issues with them feel more capable to protect children from Internet hazards regardless of their technological profiles. For such an attempt, schools could play a significant role in encouraging 
Elena VITALAKI, Panagiotes S. ANASTASIADES, George TSOUVELAS. Factors Influencing Parental Control for the Safe and Pedagogical Internet Use among Primary School Students

parent-teachers' collaborations by inviting parents to parenting talks that incorporate elements

of Internet use and safety.

Therefore, it is strongly recommended: a) the importance that families receive regular information on the dangers related to the Internet use and on how to protect and guide their children on the Internet safety, b) to provide schools with materials to use with pupils and parents aimed at developing Net literacy and safe surfing practices in and out the family home, c) to encourage family-school collaborations, in order to guide minors to develop a critical judgement when navigating the Web for various educational or recreational reasons at home and at school.

Based on this study, it would be fruitful to conduct more experimental and longitudinal studies that focus on various indicators that influence the quality of ICT usage by students in primary schools, such as family relationships/interactions, family intimacy or family bonding as well as other social contexts such as children's interaction with other peer children out the family boundaries, in school or other places. Additionally, another aspect for future research could be the examination of the effects of peer interaction and school education on children's exposure to negative Internet content. Finally, little is known about the social, physical and cognitive impacts of the Internet use on child development. Descriptive studies based on the importance of asking children directly about their beliefs and attitudes when using the Internet in and out the family settings should be also encouraged and promoted.

\section{References}

Anastasiades, P., Vitalaki, E. (2004). Information Communication Technologies in Elementary Schools: Why the Parents do Concern? Presented at the European Conference on Educational Research, ECER 2004, EERA(European Educational Research Association), University of Crete, Rethymnon - Greece, 22-25 September 2004.

Anastasiades, P. S., Vitalaki, E., \& Gertzakis, N. (2008). Collaborative learning activities at a distance via interactive videoconferencing in elementary schools: Parents' attitudes. Computers \& Education, 50, 1527-1539.

Amato, P., Fowler, F. (2002). Parenting practices, child adjustment, and family diversity. Journal of Marriage and Family, 64, 703-716.

Attewell, P., Suazo-Garcia, B., Battle, J. (2003). Computers and young children: Social benefit or social problem? Social Forces, 82 (1), 277-297.

Corbett, B. A, Willms, J. D. (2002). Information and communication technology: Access and use. Education Quarterly Review, 8 (4).

Cho, C. H., Cheon, H., J. (2005). Children's Exposure to Negative Internet Content: Effects of Family. Journal of Broadcasting \& Electronic Media, 49 (4), 488-509.

Colley, A., Comber, C. (2003). Age and gender differences in computer use and attitudes among secondary school students: what has changed? Educational Research, 45 (2), 155-165.

Cordes, C., \& Miller, E. (Eds) (2000). Fool's gold: a critical look at computers in childhood. CollegePark, MD: Alliance for Childhood. Children and computers in pre-school157@ British Educational Communications and Technology Agency, 2005.

European Opinion Research Group EEIG-Special Eurobarometer (2004). Illegal and harmful content on the Internet. European Opinion Research Group EEIG, March, 2004.

Facer Keri, Furlong John, Furlong Ruth and Sutherland Rosamund (2003). Screen Play: Children and Computing in the Home London and New York, Routledge Falmer.

Fairlie, R.W. (2005). The effects of home computers on school enrolment. Economics of Education Review, 24 (5), 533-547.

Field, A. (2005). Discovering Statistics Using SPSS (Second Edition). LTD: Sage. 
PROBLEMS

OF EDUCATION

IN THE $21^{\text {st }}$ CENTURY

Volume 42, 2012

134

Goldberg, P., D. (2004). An Exploratory Study about the Impacts that Cybersex (The use of the Internet for sexual purposes) is having on Families and the Practices of Marriage and Family Therapists. Thesis submitted to the Faculty of the Virginia Polytechnic Institute.

Gross, E., F. (2004). Adolescent Internet use: What we expect, what teens report, Applied Developmental Psychology, 25, 633-649.

Greenberg, B. S., Rampoldi-Hnilo, L., \& Mastro, D. (Eds.). (2001). The alphabet soup of the television ratings. Cresskill, NJ: Hampton Press.

Howitt, D., \& Cramer, D. (2004). SPSS 11 Statistical Package for Windows. Athens: Klitharithmos.

King, J., Bond, T., \& Blandford, S. (2002). An investigation of computer anxiety by gender and grade. Computers in Human Behaviour, 18, 69-84.

Lugaila, T. (2003). A child's day: 2000 (selected indicators of child well-being). Current Population Reports U.S. Census Bureau. Retrieved January 31, 2005 from http://www.census.gov/prod/ 2003pubs/p70-89.pdf.

Linebarger, D. L., Chernin, A. R. (2003). Young Children, Parents, Computers, and the Internet. IT \& SOCIETY, 1 (4), 87-106.

Mwesige, P.G. (2004). Cyber elites: A survey of Internet café users in Uganda. Telematics and Informatics, $21(1), 83-101$.

Michie, S., \& Nelson, L. D. (2006). Barriers women face in information technology careers. Self-efficacy, passion and gender biases. Women in Management Review, 21 (1), 10-27.

Mitchell, K. J., Finkelhor, D., \& Wolack, J. (2003). The exposure of youth to unwanted sexual material on the Internet: A national survey of risk, impact and prevention. Youth and Society, 34 (3), 330 358.

Mesch, G. S. (2003). The Family and the Internet: The Israeli Case. Social Science Quarterly, 84 (4), 1038.

Pew Internet \& American Life Report (2001). Teenage life online: The rise of instant-message generation and the Internet's impact on friendships and family relationships. Retrieved September 31, 2005 from http://www.pewinternet.org/datasets/index.asp.

Pettersson, M., Carlsson. I. (2004). Perspectives on Digital Divide-Internet Usage and Attitudes in Arusha, Tanzania. A Minor Field Study. Institution of Media Technology· Södertörn University College Bachelor's thesis, Diploma work project Stockholm 2004.

Plowman, L., Stephen, C. (2005). Children, play, and computers in pre-school education. British Journal of Educational Technology, 36 (2), 145-157.

Plowman, L., McPake, J., Stephen, C. (2010). The Technologisation of Childhood? Young Children and Technology in the Home. Children \& Society, 24, 63-74.

Pettit, G., S., Laird, R., D., Dodge, K., A., Bates, J., I., \& Criss, M., M. (2001). Antecedents and behaviorproblem outcomes of parental monitoring and psychological control in early adolescence. Child Development, 72, 583-598.

Sayer, L., C., Bianchi, S., M., \& Robinson, J., P. (2004). Are parents investing less in children? Trends in mothers' and fathers' time with children. American Journal of Sociology, 110, 1-43.

Shaw, S. M., \& Dawson, D. (2001). Purposive leisure: Examining parental discourses on family activities. Leisure Sciences, 23, 217-231.

Stafford, L., \& Canary, D. J. (1991). Maintenance strategies and romantic relationship type, gender and relational characteristics. Journal of Social Personality Relation, 8, 217-242.

Sothern, M. (2004). Obesity prevention in children: Physical activity and nutrition. Nutrition, 20, $704-$ 708.

Subrahmanyam, K., P., Greenfield, R., Kraut \& Gross E. (2001). The Impact of Computer Use on Children's and adolescents' Development. Applied Developmental Psychology, 22, 7-30.

Subrahmanyam, K. \& Greenfield, P. M. (1999). Computer Games for Girls: What Makes Them Play? In Cassell, J. and Jenkins, H. (eds.) From Barbie to Mortal Kombat: Gender and Computer Games. Cambridge, MA: The MIT Press. 
Elena VITALAKI, Panagiotes S. ANASTASIADES, George TSOUVELAS. Factors Influencing Parental Control for the Safe and Pedagogical Internet Use among Primary School Students

Tein, J., Roosa, M., \& Michaels, M. (1994). Agreement between parent and child reports of parental behaviors. Journal of Marriage and the Family, 56, 341-355.

Valcke, M., Schellens, T., Van Keerand, H., Gerarts' M. (2007). Primary school children's safe and unsafe use of the Internet at home and at school: An exploratory study. Computers in Human Behavior, 23 (6), 2838-2850

Vandewater, E.A., Park, S., Huang, X., \& Wartellios, E.A., (2005). No-you can’t watch that-Parental rules and young children's media use. American Journal Scientist, 48, 603-623.

Veckiri, I., \& Chronaki, A. (2008). Gender issues in technology use: Perceived social support, computer self-efficacy and value beliefs, and computer use beyond school. Computers \& Education, 51 (3), 1392-1404.

Wong, P. K. (2002). ICT production and diffusion in Asia: Digital dividends or digital divide? Information Economics and Policy, 14 (2), 167-187.

Wang, R., Bianchi, S. M., Raley, S. B. (2005). Teenagers' Internet Use and Family Rules: A Research Note. Journal of Marriage and Family, 5 (67), 1249.

Yeora, K. (2003). The Impact of the Internet on Children's Daily Lives: Physical, Social and Psychological Well-Being. Doctoral Thesis, University of Georgia.

Yankelovich Partners. (1999). A study of teens and their use of the Internet. Retrieved October 1, 2004 from http://www.websense.com/news/090799.htm.

Zhu, J. J. H., \& He, Z. (2002). Diffusion, Use and Impact of the Internet in Hong Kong: A Chain Process. Journal of Computer-Mediated Communication. Retrieved from http://www.ascusc.org/.

Advised by Laima Railiene, University of Siauliai, Lithuania

Received: January 22, 2012

Accepted: March 18, 2012

\begin{tabular}{|ll|}
\hline Elena Vitalaki & $\begin{array}{l}\text { Dr., Lecturer, University of Crete, Dimitrakaki 33, 74100, Rethymnon, } \\
\text { Greece. } \\
\text { E-mail: vitalaki@edc.uoc.gr }\end{array}$ \\
\hline Panagiotes S. Anastasiades & $\begin{array}{l}\text { Dr., Assistant Professor, Department of Education at the University of } \\
\text { Crete, Greece. }\end{array}$ \\
\hline George Tsouvelas & $\begin{array}{l}\text { MSc, Visiting Tutor, Department of Psychology at the National Kapodistrian } \\
\text { University of Athens, Greece. }\end{array}$ \\
\hline
\end{tabular}

